\title{
A extensão universitária no Brasil e seus desafios durante a pandemia da COVID-19
}

\author{
University extension in Brazil and its challenges during the COVID-19 pandemic \\ Universidad en Brasil y sus retos durante la pandemia COVID-19
}

Recebido: 15/02/2021 | Revisado: 21/02/2021 | Aceito: 24/02/2021 | Publicado: 03/03/2021

Cláudia Batista Mélo

ORCID: https://orcid.org/0000-0001-5300-3510 Universidade Federal da Paraíba, Brasil

E-mail: claudia.melo@academico.ufpb.br

Gabrieli Duarte Farias

ORCID: https://orcid.org/0000-0001-6904-2856 Universidade Federal da Paraíba, Brasil

E-mail: gabrieli.duarte@academico.ufpb.br

Vitória Régia Rolim Nunes

ORCID: https://orcid.org/0000-0003-3460-9503 Universidade Federal da Paraíba, Brasil

E-mail: vitoria.nunes@academico.ufpb.br

Tifany Shela Albuquerque Borba de Andrade

ORCID: https://orcid.org/0000-0002-5266-3004 Universidade Federal da Paraíba, Brasil

E-mail: tifany.andrade@academico.ufpb.br

Carmem Silvia Laureano Dalle Piagge

ORCID: https://orcid.org/0000-0001-7999-2943

Universidade Federal da Paraíba, Brasil

E-mail:carmem.piagge@academico.ufpb.br

\begin{abstract}
Resumo
O cenário atual, permeado por desafios devido à pandemia da COVID-19, fez com que as ações extensionistas promovidas por Instituições de Ensino Superior (IES) brasileiras tivessem que se readequar. O objetivo deste estudo é retratar os caminhos percorridos por tais instituições para adaptar ações já existentes e desenvolver novas que atendessem às necessidades encontradas. Esse trabalho caracteriza-se como pesquisa documental, descritiva, qualitativa e quantitativa sobre a extensão acadêmica durante a pandemia da COVID-19. Utilizou-se dados primários, em domínio público, como editais, regulamentos e notícias disponíveis nos websites das instituições, buscando-se responder variáveis pré-estabelecidas. A população (129) abarcou as IES federais e estaduais disponibilizadas no website do eMEC, sendo a amostra 126. Como parte dos resultados encontrados, $87,5 \%$ das IES públicas optaram por continuar as ações de extensão durante 2020 , com $87,9 \%$ sendo adaptadas e $71,8 \%$ com flexibilização das normas. As modalidades extensionistas, tais como projetos (90,3\%), programas $(75 \%)$, cursos $(78,2 \%)$ e eventos $(75 \%)$, foram expressivamente realizadas. Todavia, apenas $51 \%$ das IES apresentaram prestação de serviços. Ações destinadas ao enfrentamento da COVID-19 envolveram disponibilização de informações (34\%), confecção/entrega de materiais destinados a prevenção (12\%) e realização de atendimento aos casos (4\%). $24 \%$ das instituições publicaram edital de extensão com vigência para 2021 com adequações à pandemia, enquanto 38\% publicaram edital sem adequações. Conclui-se que a extensão foi adaptada às necessidades desencadeadas pela pandemia da COVID-19 e ações de enfrentamento foram desenvolvidas para amenizar o cenário pandêmico.
\end{abstract}

Palavras-chave: COVID-19; Ensino; Extensão; Instituições de ensino superior.

\begin{abstract}
The current scenario, permeated by challenges due to the COVID-19 pandemic, caused the extension actions promoted by Brazilian Higher Education Institutions (HEIs) to be adapted. The aim of this study is to portray the paths taken by such institutions to adapt existing actions and develop new ones that meet the needs found. This work is characterized as documentary, descriptive, qualitative and quantitative research on the academic extension during the COVID-19 pandemic. Primary data were used in the public domain, such as edicts, regulations and news available on the institutions' websites, seeking to answer pre-established variables. The population (129) boarded the federal and state HEIs available on the e-MEC website, with sample 126. As part of the results found, $87.5 \%$ of the public HEIs chose to continue extension actions during 2020 , with $87.9 \%$ being adapted and $71.8 \%$ with easing of standards. Extension modalities, such as projects $(90.3 \%)$, programs $(75 \%)$, courses $(78.2 \%)$ and events $(75 \%)$, were significantly performed. However, only $51 \%$ of the HEIs provided services. Actions aimed at confronting COVID-19 involved the provision of information (34\%), preparation/delivery of materials intended for prevention (12\%) and case care $(4 \%)$. $24 \%$ of the institutions published an extension notice valid for 2021 with adaptations to the pandemic, while $38 \%$ published an
\end{abstract}


unsuitable notice. Can be concluded that the extension was adapted to the needs triggered by the COVID-19 pandemic and coping actions were developed to mitigate the pandemic scenario.

Keywords: COVID-19; Extension; Higher education institutions; Teaching.

\section{Resumen}

El escenario actual, impregnado de desafíos debido a la pandemia COVID-19, hizo que se adaptaran las acciones de extensión promovidas por las Instituciones Brasileñas de Educación Superior (IES). El objetivo de este estudio es retratar los caminos dados por estas instituciones para adaptar las acciones existentes y desarrollar otras nuevas que satisfagan las necesidades encontradas. Este trabajo se caracteriza por ser una investigación documental, descriptiva, cualitativa y cuantitativa sobre la extensión académica durante la pandemia COVID-19. Los datos primarios se utilizaron en el dominio público, como edictos, reglamentos y noticias disponibles en los sitios web de las instituciones, buscando responder a variables preestablecidas. La población (129) abordó las IES federales y estatales disponibles en el sitio web de e-MEC, con la muestra 126. Como parte de los resultados encontrados el 87,5\% de las IES públicas optaron por continuar las acciones de prórroga durante 2020, con el 87,9\% adaptado y el 71,8\% con la flexibilización de las normas. Modalidades de extensión, como proyectos $(90,3 \%)$, programas $(75 \%)$, cursos $(78,2 \%)$ y los eventos (75\%), se realizaron significativamente. Sin embargo, sólo el 51\% de las IES prestaban servicios. Las acciones encaminadas a hacer frente a COVID-19 implicó el suministro de información (34\%), preparación/entrega de materiales destinados a la prevención (12\%) y el cuidado de casos (4\%). El 24\% de las instituciones publicaron un aviso de prórroga válido para 2021 con adaptaciones a la pandemia, mientras que el $38 \%$ publicó un aviso inadecuado. Se concluye que la extensión se adaptó a las necesidades desencadenadas por las acciones de pandemia y afrontamiento COVID-19 para mitigar el escenario de la pandemia.

Palabras clave: COVID-19; Ensenãnza; Extensión; Instituciones de educación superior.

\section{Introdução}

Em dezembro de 2019, uma pneumonia de origem desconhecida foi encontrada em um conjunto de casos em Wuhan, na China. O patógeno causador tratava-se do novo coronavírus (SARS-CoV-2) que passou a atrair grande atenção nacional e internacional em decorrência da rápida disseminação. Tal patógeno está relacionado à propagação da COVID-19, considerada pandemia pela Organização Mundial da Saúde (OMS), em março de 2020. Desde então, grande foi o impacto do novo coronavírus na saúde pública, em razão do alto número de casos relatados e elevada mortalidade em um curto período de tempo, sendo o distanciamento social a principal estratégia para mitigar a propagação (Jiang et al., 2020; Santos et al., 2020; Bernal, Siqueira, Adami, \& Santos, 2020).

As manifestações clínicas mais comuns em pacientes infectados pelo SARS-CoV-2 são: febre (90\% ou mais), tosse (cerca de 75\%) e dispneia (até 50\%), destacando-se a febre e os sintomas respiratórios como os presentes em grande parte dos casos. Um grupo reduzido, porém significativo de pacientes apresenta sintomas gastrointestinais. Vale salientar que idosos e pessoas com comorbidades, por apresentarem função imunológica mais debilitada, são mais suscetíveis às infecções e suas consequências, apresentando uma taxa de mortalidade particularmente relevante (Jiang et al., 2020; Orte, Sánchez-Prieto, Domínguez, \& Barrientos-Báez, 2020). Em janeiro de 2021, mais de 8 milhões de casos haviam sido registrados no Brasil e o total acumulado de óbitos chegava a mais de 200 mil. A indústria farmacêutica em parceria com instituições científicas tem trabalhado com o objetivo de desenvolver e implantar vacinas e medicamentos seguros e eficazes para combater a COVID-19. Enquanto isso, as ações de enfrentamento devem continuar a fim de suprimir a transmissão e reduzir a mortalidade (World Health Organization, 2021a; World Health Organization, 2021b).

A magnitude da pandemia da COVID-19 desencadeou diversas transformações e as Instituições de Ensino Superior (IES) brasileiras passaram a enfrentar desafios no que concerne ao desenvolvimento das atividades acadêmicas. Em face da necessidade de promover o distanciamento social a fim de conter a disseminação do novo coronavírus, seguindo a recomendação mundial, as IES tiveram que suspender as atividades presenciais, o que fez com que algumas implantassem atividades remotas. Com a pandemia, tais instituições passaram a ser desafiadas no que se refere ao desenvolvimento de suas atividades junto à comunidade, sendo necessária a realização de readequações. Desse modo, as ações de extensão continuaram promovendo a produção e disseminação do conhecimento universitário, sendo de suma relevância para a sociedade (Falcão \& Gomes, 2020; 
Diniz et al., 2020).

A extensão na educação superior brasileira é regulamentada segundo a Constituição de 1988, buscando estabelecer o vínculo entre universidade e sociedade, fazendo assim, parte do tripé acadêmico, junto com a pesquisa e o ensino, visando desenvolver democracia, equidade e ética. Sendo assim, a extensão é uma forma de ensino e aprendizagem que instiga os acadêmicos a buscar o conhecimento sobre a realidade de inúmeras questões sociais (Silva \& Kochhann, 2018; Steigleder, Zucchetti \& Martins, 2019; Forproex, 2012).

Em 1998, elaborou-se a proposta do Plano Nacional da Extensão (PNE), a qual defendia a extensão com um viés acadêmico, indo em contrapartida com suas ações anteriores, como a prestação de serviços. O Plano Nacional de Extensão Universitária, criado em 2001, aborda que as atividades da extensão visam transformações de cunho social e de interesse acadêmico, validando assim, a extensão como colaboradora da formação de alunos e professores, através de atividades voltadas para a sociedade. Além disso, esse plano estabelece que, no mínimo, 10\% dos créditos dos cursos de graduação sejam cumpridos em ações extensionistas, de modo que o acadêmico atue de forma efetiva, não apenas em eventos e cursos (Silva \& Kochhann, 2018). A lei $n^{\circ}$ 13.005/2014, que regulamenta o Plano Nacional de Educação 2014-2024, em sua meta 12.7, reforça o ideal da curricularização mínima de $10 \%$ da extensão universitária, estabelecendo que sua inclusão em projetos pedagógicos dos cursos (PPC) demonstra importância na formação acadêmica e na construção do conhecimento (Forproex, 2012; Forproex, 2001).

A extensão universitária possui caráter social, educativo, científico, cultural e tecnológico, podendo ser dividida nas seguintes modalidades: projetos; programas; cursos e oficinas; eventos; e prestação de serviços. Os projetos se caracterizam como um conjunto de ações de extensão, em geral, correlacionadas com a pesquisa e o ensino, buscando objetivos específicos e direcionados para atender demandas e gerar mudanças tanto em instituições como em grupos sociais, normalmente, com prazo de 1 ano. Os programas de extensão são mais amplos no que se refere aos seus objetivos e diretrizes institucionais. Nele, há a articulação de projetos a outras ações, como cursos e prestação de serviços, podendo ser realizado de médio a longo prazo (Brasil, 2018; Proex/ufpb, 2011). Os cursos e oficinas de extensão são ações com atuação teórica/prática, podendo ocorrer de modo presencial ou à distância. Apresentam carga horária de no mínimo oito horas e critérios de avaliação estabelecidos previamente. Os eventos são caracterizados pela apresentação/exibição de conhecimento ou produto cultural, artístico, esportivo, científico e tecnológico. São considerados eventos de extensão congressos, exposições, festivais, seminários, espetáculos, ciclos de debates, eventos esportivos, campanhas entre outras determinadas ações. Por fim, as prestações de serviços são ações que podem ser realizadas por participantes da universidade de modo gratuito ou por terceiros contratados como Organizações Não Governamentais e instituições públicas. São consideradas prestações de serviços de extensão: atendimento ao público em espaços de cultura, ciência e tecnologia; exames e laudos; serviços de assessoria/consultoria; criação de patentes; atendimento jurídico e judicial; atendimento em saúde para a sociedade e para os animais, entre outras ações (Proex/ufpb, 2011).

Sabendo que a extensão tem a capacidade de se moldar às necessidades do contexto em que está inserido, torna-se relevante avaliar como essa atividade acadêmica se desenvolveu perante a pandemia da COVID-19, no ano de 2020 e como suas ações contribuíram para o enfrentamento da problemática em questão. Desse modo, busca-se identificar: as ações de extensão foram suspensas ou continuaram com adaptações e flexibilização em suas normas? Quais modalidades de extensão foram realizadas? Foram realizadas ações voltadas ao enfrentamento da COVID-19? Como as instituições estão planejando suas atividades em 2021? Assim, o objetivo deste estudo é relatar e discutir as ações extensionistas realizadas pelas Instituições de Ensino Superior brasileiras no ano de 2020, dando enfoque às atividades que tiveram a COVID-19 como tema principal.

\section{Metodologia}

Este estudo caracteriza-se como uma pesquisa documental, descritiva, qualitativa e quantitativa (Pereira et al., 2018) sobre o desenvolvimento das ações de extensão nas IES, considerando as categorias administrativas federais e estaduais do Brasil 
durante o período de pandemia da COVID-19. Cabe ressaltar a importância da execução das pesquisas de natureza documental, pois através do tratamento analítico dos dados primários, há o favorecimento do processo de compreensão e maturação do objeto estudado (Sá-Silva, Almeira, \& Guindani, 2009). Neste caso, a relevância aplica-se na análise do processo de contribuição das ações de extensão para o enfrentamento da COVID-19, a fim de entender a importância da continuidade das ações de extensão durante esse período, bem como, observar as adaptações e as flexibilizações realizadas.

Desse modo, utilizou-se dados primários, em domínio público, dispensando a submissão ao Comitê de Ética e Pesquisa, conforme regulamenta a Instrução Normativa n 510/2016 (Brasil, 2016). A população foi composta por todas as IES federais e estaduais do Brasil, que contabilizam 129 instituições, conforme disponibilizado no website do e-MEC (Brasil, 2017). Enquanto a amostra foi constituída por todas as IES que formalizaram a extensão como atividade curricular, que juntas somam 126 instituições.

A Figura 1 exibe como ocorreu a distribuição da amostra por categoria administrativa: instituições estaduais e federais; e organização acadêmica: faculdades, centros universitários e universidades.

Figura 1. Distribuição da amostra por categoria administrativa e organização acadêmica.

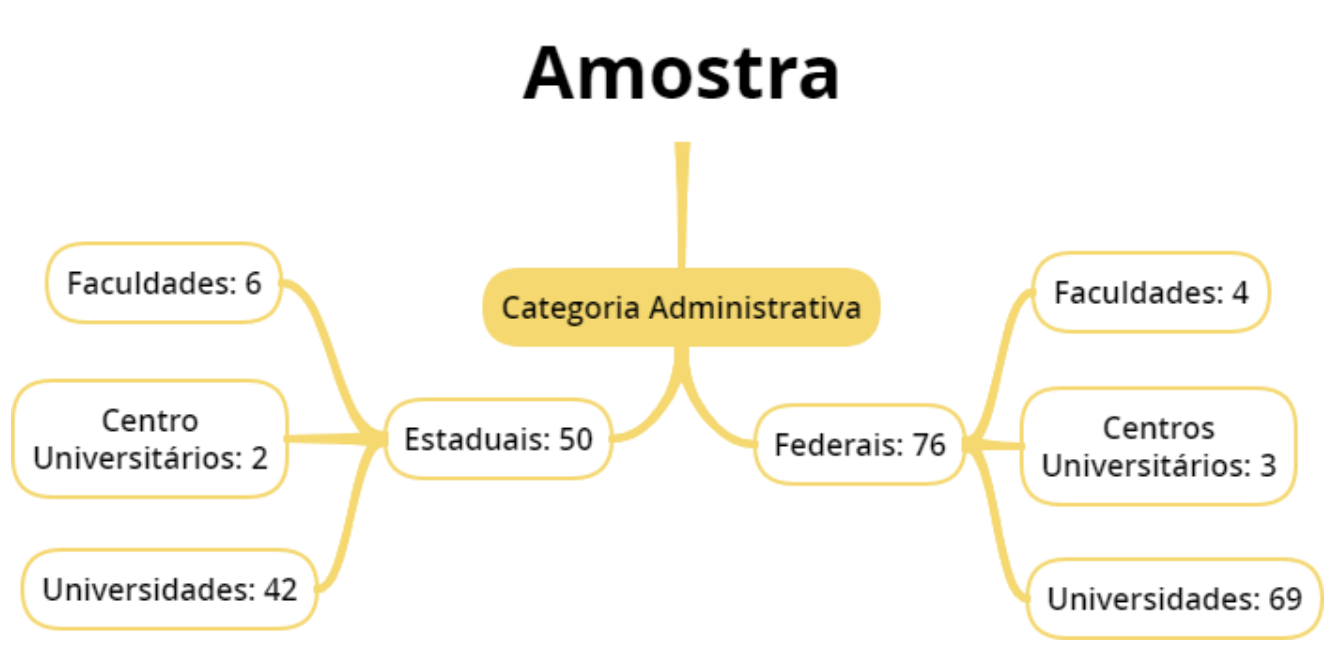

Fonte: Autores.

Inicialmente, realizou-se a leitura flutuante dos editais, regulamentos e notícias contidas nos websites, sob análise crítica da autenticidade e veracidade. Em seguida, selecionou-se os documentos usados para sintetizar as variáveis e categorizá-las. Posteriormente, foi feita a coleta dos dados, que ocorreu entre 07 a 23 de dezembro de 2020, sendo visitados 126 websites, porém 10 não possuíam informações públicas sobre o desenvolvimento de ações extensionistas durante a pandemia da COVID-19. A busca foi realizada com base no objeto do estudo e teve o intuito de esgotar as informações, investigando a situação das IES estaduais e federais, quanto a continuidade das ações de extensão e se houve adaptação e flexibilização das normas, além de observar o desenvolvimento das ações de extensão direcionadas ao enfrentamento da COVID-19.

Por fim, utilizou-se o programa SPSS (Statistical Package for the Social Sciences), na versão 23.0, para realizar a digitação dos dados e análise estatística descritiva, obtendo frequências absolutas e relativas para as variáveis categóricas, alcançando resultados para as perguntas propostas.

\section{Resultados}

Após análise minuciosa das páginas web, identificou-se que o percentual das IES públicas que possuem a extensão formalizada como atividade curricular e que continuaram exercendo suas ações durante a pandemia da COVID-19 foi de 78,6\%, 
no Brasil. Observou-se que as instituições da região Centro-oeste apresentaram maior adesão ao processo de continuidade das ações extensionistas (91,6\%), em contrapartida, apenas 56,1\% das IES da região Sudeste continuaram com a extensão no momento inicial da pandemia. A Tabela 1, exibe detalhadamente a situação da extensão durante a pandemia da COVID-19, em cada região do Brasil.

Tabela 1. Situação das ações de extensão desenvolvidas nas IES públicas do Brasil, durante a pandemia da COVID-19, em cada região do Brasil.

\begin{tabular}{|c|c|c|c|c|}
\hline & $\begin{array}{l}\text { Foram } \\
\text { suspensas }\end{array}$ & $\begin{array}{l}\text { Não foram } \\
\text { suspensas }\end{array}$ & $\begin{array}{l}\text { Foram suspensas } \\
\text { e depois retomadas }\end{array}$ & $\begin{array}{l}\text { Não } \\
\text { informado }\end{array}$ \\
\hline & $0 \%$ & $87,5 \%$ & $6,25 \%$ & $6,25 \%$ \\
\hline & $0 \%$ & $89,2 \%$ & $5,4 \%$ & $5,4 \%$ \\
\hline & $8,4 \%$ & $91,6 \%$ & $0 \%$ & $0 \%$ \\
\hline & $5 \%$ & $90 \%$ & $5 \%$ & $0 \%$ \\
\hline
\end{tabular}

Fonte: Autores.

A ininterrupção das atividades de extensão foi possível através do planejamento de ações adaptadas, as quais passaram a ser realizadas de forma virtual/remota ou adotando protocolos rígidos de biossegurança. Além disso, a adoção de normas mais flexíveis, como permitir mudanças no plano de trabalho ou adiar o cronograma, facilitou a continuidade das ações. Das extensões que não suspenderam suas ações, $87,9 \%$ foram adaptadas e 71,8\% tiveram as normas flexibilizadas, como mostra a Tabela 2.

Tabela 2. Adaptação das ações e flexibilização das normas de extensão durante a pandemia da COVID-19.

\begin{tabular}{|l|c|}
\hline VARIÁVEL & PORCENTAGEM \% \\
\hline Foram Adaptadas & $87,9 \%$ \\
Sim & $12,1 \%$ \\
Não informado & $100 \%$ \\
TOTAL & \\
Houve Flexibilização das Normas & $71,8 \%$ \\
Sim & $0,8 \%$ \\
Não & $27,4 \%$ \\
Não informado & $100 \%$ \\
TOTAL & \\
\hline
\end{tabular}

Fonte: Autores.

A Figura 2 disponibiliza informações no que concerne aos tipos de ações desenvolvidas pelas extensões durante o período da pandemia. Foi observado que 90,3\% das IES públicas do Brasil realizaram projetos de extensão; 78,2\% ofertaram cursos de extensão para o público externo ou interno, que foram feitos de forma virtual, através do Google Meet, Zoom e Ambiente Virtual de Aprendizagem (AVA); 75\% realizaram eventos, 51\% realizaram prestação de serviços e $75 \%$ realizaram programas de extensão. 
Figura 2. Ações desempenhadas pelas extensões durante a pandemia da COVID-19.

$\begin{array}{ll}\square \text { Realizaram projetos } & \square \text { Realizaram cursos } \\ \square \text { Realizaram eventos } & \square \text { Realizaram prestação de serviços } \\ \square \text { Realizaram programas } & \end{array}$

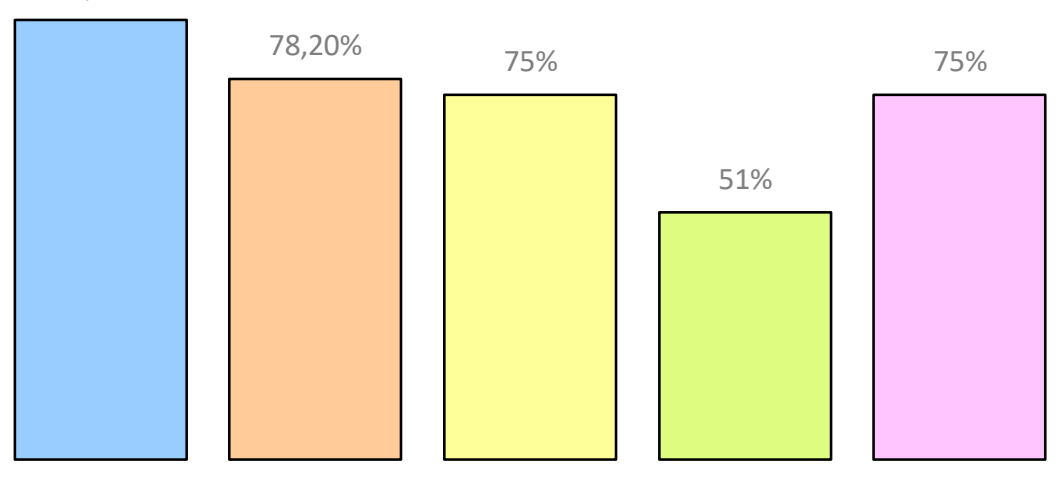

Fonte: Autores.

A maioria das IES que continuaram com as ações de extensão estabeleceram planos de trabalho voltados para o enfrentamento da COVID-19. Entre as categorias administrativas, as instituições federais contribuíram com a maior parte das ações (84\%). Com relação às organizações acadêmicas, 89\% das universidades realizaram ações para enfrentamento da COVID19, por outro lado, apenas $20 \%$ das faculdades desenvolveram esse tipo de atividade, como exibido na Tabela 3.

Tabela 3. Distribuição, em porcentagem, das IES que realizaram ações destinadas ao enfrentamento da COVID-19, por categoria administrativa e organização acadêmica.

\begin{tabular}{|c|c|c|c|c|}
\hline \multicolumn{5}{|c|}{ Realização de ações para enfrentamento da COVID-19 } \\
\hline & & Sim & Não & Não informado \\
\hline \multirow{2}{*}{$\begin{array}{l}\text { Categoria } \\
\text { administrativa }\end{array}$} & Estadual & \multirow{5}{*}{$\begin{array}{c}79,5 \% \\
84 \% \\
89 \% \\
20 \% \\
60 \%\end{array}$} & \multirow{5}{*}{$\begin{array}{c}4,1 \% \\
10,7 \% \\
7,3 \% \\
20 \% \\
0 \%\end{array}$} & \multirow{2}{*}{$\begin{array}{c}16,4 \% \\
5,3 \%\end{array}$} \\
\hline & Federal & & & \\
\hline \multirow{3}{*}{$\begin{array}{l}\text { Organização } \\
\text { acadêmica }\end{array}$} & Universidade & & & $3,7 \%$ \\
\hline & Faculdade & & & $60 \%$ \\
\hline & $\begin{array}{l}\text { Centro } \\
\text { Universitário }\end{array}$ & & & $40 \%$ \\
\hline
\end{tabular}

Fonte: Autores.

As ações desenvolvidas pelas instituições para o enfrentamento da COVID-19, foram classificadas em: disponibilização de informações em páginas virtuais para prevenção e combate à COVID-19; realização de atendimentos aos casos de suspeita do novo coronavírus, através da telemedicina ou por meio da disponibilização dos testes de COVID-19; produção/entrega de materiais, como álcool em gel $70 \%$ ou máscaras. Diante disso, observou-se que 34\% das IES públicas disponibilizaram informações, $12 \%$ produziram/entregaram materiais para prevenção, $4 \%$ prestaram atendimento aos casos de suspeita do novo coronavírus e 50\% realizaram mais de um tipo de ação, de acordo com a Figura 3. 
Figura 3. Ações desenvolvidas para o enfrentamento da COVID-19.

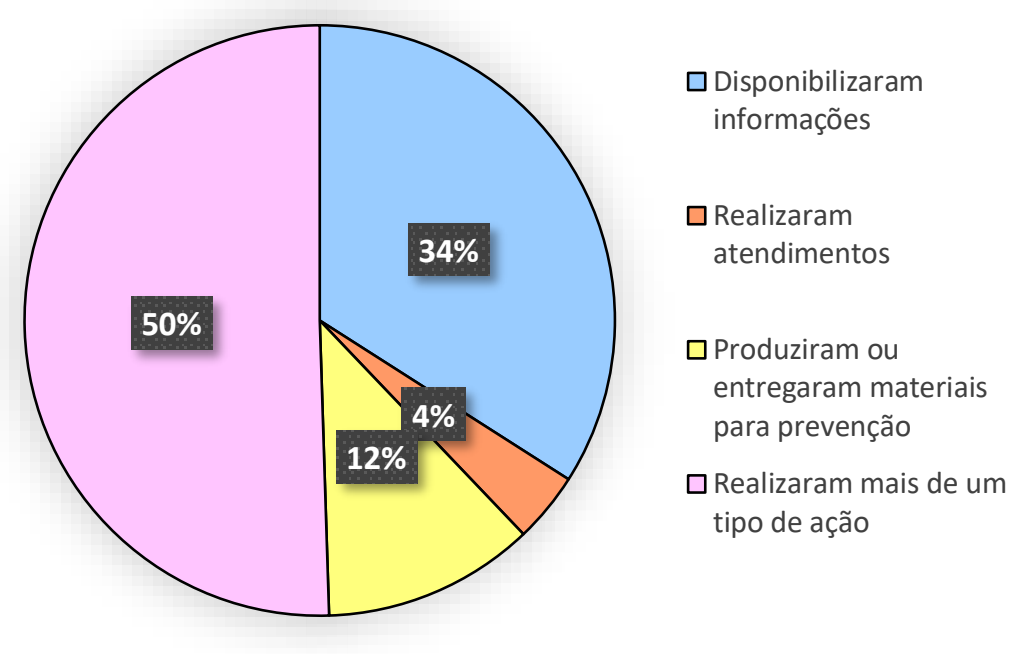

Fonte: Autores.

Das instituições que realizaram mais de um tipo de ação para enfrentamento da COVID-19, 49\% disponibilizaram informações, produziram/entregaram materiais e também realizaram atendimentos, 41,2\% disponibilizaram informações e produziram/entregaram materiais para prevenção do novo coronavírus, 7,8\% disponibilizaram informações e realizaram atendimentos e $2 \%$ realizaram atendimentos e produziram/entregaram materiais, conforme disposto na Figura 4.

Figura 4. Porcentagem das IES públicas que realizaram mais de um tipo de ação para o enfrentamento da COVID-19.

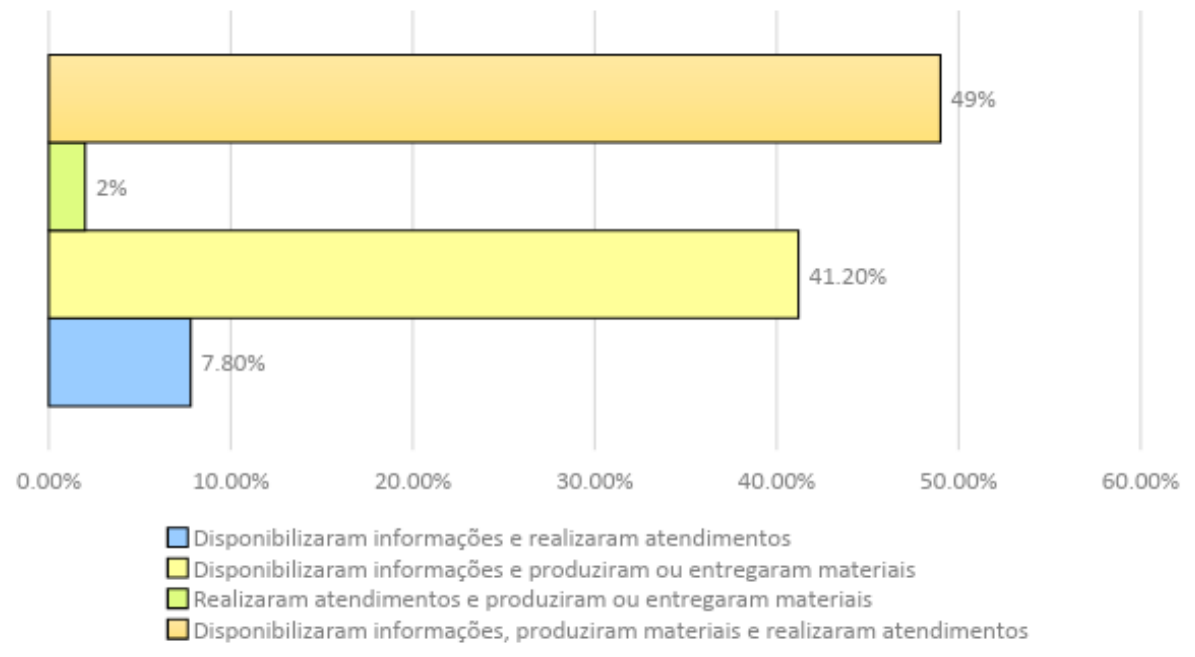

Fonte: Autores.

Com relação ao planejamento da extensão para a vigência no ano de 2021, verificou-se uma baixa tendência ao desenvolvimento de planos de trabalho adaptados à pandemia. Desse modo, 24\% das IES públicas do Brasil já publicaram edital de extensão com adequações à pandemia, enquanto 38\% publicaram edital sem adaptações e $37 \%$ não informaram sobre a publicação de edital com vigência para o ano de 2021, conforme exibido na Figura 5. 
Figura 5. Porcentagem das IES que publicaram edital com vigência para 2021 com adequações à pandemia.

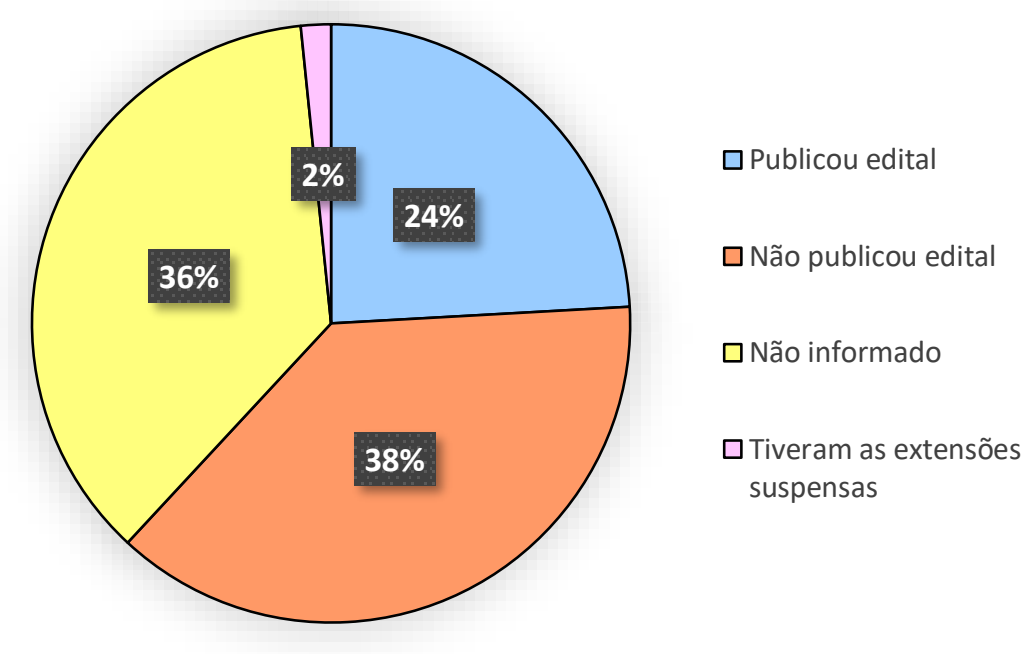

Fonte: Autores.

\section{Discussão}

A necessidade de conter a pandemia, através do estabelecimento de medidas preventivas que priorizaram o distanciamento social nas repartições públicas e privadas, fizeram com que as IES suspendessem as aulas ou adotassem o ensino remoto (Brasil, 2020). Segundo Bezerra e colaboradores (2020), 47,5\% das universidades estaduais do Brasil ofertaram o ensino remoto, enquanto $10 \%$ optaram por não continuar com as aulas. No entanto, quando se refere às ações de extensão, exige-se maior cautela no processo de decisão da suspensão, tendo em vista que elas são capazes de contribuir com a prestação de serviço durante a pandemia, proporcionando apoio e atendimento às comunidades vulneráveis (Ricci, Dimov, Cassais, \& Dellbrügger, 2020). Desse modo, a curricularização da extensão, que já representava um desafio para as instituições, tornou-se motivo para mais dificuldades e limitações durante a pandemia, principalmente em algumas regiões do Brasil (Gusso et al., 2020; Steigleder et al., 2019). Isso pode ser observado ao analisar o percentual das universidades públicas que continuaram com as ações de extensão durante a pandemia na região Sudeste, evidenciando nível inferior comparado ao percentual das universidades públicas do Brasil.

No início da pandemia, algumas universidades localizadas na região Sudeste enfrentaram dificuldades para manter as atividades de extensão e optaram inicialmente pela suspensão dos planos de trabalho, que só foram retomados posteriormente, após uma série de planejamentos. Por outro lado, a maioria das universidades conseguiram contornar os desafios e não suspenderam as ações de extensão. Essa atitude positiva foi consequência das medidas de adaptações e flexibilização das normas adotadas pelas IES, que passaram a utilizar recursos virtuais e adotaram protocolos rígidos de biossegurança. Esses resultados foram semelhantes aos encontrados por Mélo, Farias, Moisés, Beserra e Piagge (2020), que relataram que cerca de 95,2\% das universidades federais do Brasil não suspenderam os planos de trabalho das atividades de extensão e dentre essas, 93,2\% adaptaram e flexibilizaram as normas de extensão, a fim de permitir a continuidade das atividades.

As ações de extensão podem ser praticadas através de projetos, programas, cursos, eventos e prestação de serviços, as quais, em decorrência da pandemia da COVID-19, passaram a encontrar desafios para se adaptar. Diniz e colaboradores (2020) destacam alguns destes desafios, considerando as dificuldades de mobilidade para a realização das ações, o cumprimento do distanciamento social e das medidas de higienização, além do uso de Equipamentos de Proteção Individual (EPI) pelos extensionistas e pelos participantes. Diante de tais desafios e objetivando atender as recomendações de isolamento social, um número considerável de instituições não realizou atividades presenciais, encontrando no modelo remoto uma forma de 
permanecer interagindo com a comunidade.

Uma modalidade que encontrou vantagens no quesito remoto foram os eventos, realizados em grande parte das IES, tendo em vista a maior facilidade de contato com o público quando realizado de maneira on-line, além de uma maior abrangência dos participantes, algo que encontra limitações no formato presencial. Tais eventos puderam ser realizados na forma de lives, webnários, encontros e simpósios. Algumas IES promoveram lives que abarcaram os mais variados assuntos, especialmente os relacionados às principais mudanças enfrentadas pela sociedade no contexto atual, como é o caso da Universidade Estadual do Rio Grande do Norte (UERN) através da ação "Saberes e resistências em tempos de pandemia", que consiste em aulas virtuais pelo YouTube com o objetivo de fomentar diálogos entre a instituição e a sociedade que promovam a valorização do conhecimento científico, reconhecendo-o como uma forma de resistência em um cenário pandêmico (Silva, Mascarenhas, Dutra, Silva, \& Dias, 2020).

Projetos e programas também foram expressivamente realizados neste cenário, sendo os projetos realizados em 90,3\% e os programas em 75\% das IES. Alguns projetos mantiveram o mesmo enfoque temático, fazendo uso das redes sociais e das Tecnologias da Informação e Comunicação (TIC) para se adaptar ao novo cenário, enquanto outros mudaram o enfoque do projeto uma forma de se adequar ao cenário atual, como foi o caso do projeto da Universidade Estadual da Paraíba (UEPB) que abordava sobre descarte consciente de medicamentos e passou a orientar sobre o descarte correto de EPI em decorrência da COVID-19 (Lopes, 2020). Falcão e Gomes (2020) destacam o projeto de extensão "Cine Luce" que consiste em discussões online, permeadas por materiais audiovisuais, sobre o lazer na sociedade contemporânea, destacando o uso da Internet como potencializador do fluxo comunicacional, permitindo um maior alcance mesmo durante o isolamento social. Lima, Andrade, Nunes, Vieira e Mélo (2020, p. 53) abordam a adequação do projeto de extensão "MelhorArt", o qual, por meio das redes sociais conseguiu diminuir o impacto da pandemia em suas ações antes realizadas com crianças hospitalizadas e idosas em instituições de longa permanência.

Os programas também enfrentaram desafios, especialmente os que prestam assistência a grupos mais suscetíveis a COVID-19, como é o caso dos idosos, considerando também a dificuldade de inserção deste grupo no mundo tecnológico. Um outro tipo de programa que merece destaque são os que prestam cursinho pré-vestibular, os quais encontraram no ensino remoto uma forma de abranger um maior público-alvo, em virtude da realização on-line das aulas. Ana Gabriela Silva e colaboradores (2020) retratam uma ação promovida pelo programa de extensão "Amizade Compatível - uma doação para a vida": realização de encontros on-line a fim de promover a conscientização da comunidade acadêmica e externa no que se refere a doação de sangue e de medula óssea. Os autores destacam o grande alcance obtido através da plataforma on-line e a necessidade de trazer aos ouvintes as dificuldades dos hemocentros em manterem seus estoques de sangue em tempos de pandemia.

Os cursos de extensão foram realizados em 78,2\% das instituições analisadas. Um tema abordado em cursos promovidos por diversas instituições foi a formação de docentes e discentes quanto ao uso das TIC, a fim de adaptá-los ao modelo remoto de ensino. Um exemplo a ser mencionado também é o oferecimento deste mesmo tipo de preparação aos professores da rede básica de ensino. Mélo e colaboradores (2020) destacam que cerca de 60\% das universidades federais ofertaram tal tipo de capacitação, o que corrobora a ideia de que esta preparação não foi ofertada em um número considerável de instituições. Barbosa, Ferreira e Kato (2020) retratam o desenvolvimento do curso on-line "Escolas e territorialidades em contextos de incertezas: construindo BIONAS" que objetiva promover reflexões acerca da atual situação do campo educacional neste contexto de crise, podendo então fomentar a criação de estratégias que se façam necessárias. Uma das principais vantagens do modelo remoto foi a participação de professores de diferentes níveis escolares.

A prestação de serviços esteve presente em apenas $51 \%$ das instituições analisadas, o que reflete a dificuldade das mesmas em continuar atendendo as necessidades da comunidade em um período em que o isolamento social se faz necessário. Assessorias, consultorias, atendimentos jurídicos, dentre outros exemplos, foram algumas das ações de prestação de serviços 
encontradas nas IES. Sandro Silva e colaboradores (2020) expõem a situação de vulnerabilidade e incerteza econômica enfrentada por várias famílias, destacando a necessidade de promover ações que gerem oportunidades e auxiliem os grupos sociais mais vulneráveis a adaptarem-se ao contexto atual. As ações extensionistas mencionadas no artigo objetivam viabilizar a criação de oportunidades de produtividade diante de novas demandas decorrentes da COVID-19, além de assessorar grupos já existentes quanto à adequação às novas dinâmicas de comercialização.

As universidades federais foram as que se destacaram no que se refere a realização de ações para o enfrentamento da COVID-19 e apenas 20\% das faculdades executaram essas ações. O Ministério da Educação (MEC), ao conceituar faculdades, centros universitários e universidades, destaca que as universidades são caracterizadas pela indissociabilidade entre ensino, pesquisa e extensão (Brasil, 2006). Contudo, é necessário mencionar que o desenvolvimento dos três pilares é facultativo às faculdades, o que pode explicar a baixa adesão das mesmas à realização das ações supracitadas.

Segundo o estudo em questão, com as ações de enfrentamento da COVID-19, foi possível perceber que as IES conseguiram "reafirmar a Extensão Universitária como processo acadêmico definido e efetivado em função das exigências da realidade" (Forproex, 2012, p. 9). Sendo assim, elas atuam no contexto da pandemia da COVID-19, como local de enfrentamento, multidimensional a este desafio mundial (Silva et al., 2020).

Como exemplos, a UERN realizou ações de extensão voltadas à pandemia, com projetos direcionados à produção de máscaras para doação no município de Mossoró, no Rio Grande do Norte (RN); desenvolvimento de materiais informativos em imagens, áudios e vídeos para compartilhamento em sites, redes sociais e rádios da região (Silva et al., 2020). Não obstante, o teleatendimento se mostrou presente no projeto de extensão "UEL pela vida e contra o coronavírus", da Universidade Estadual de Londrina (UEL), localizado no Paraná, com atendimento por meio de plataformas virtuais e call center (Campos et al., 2020). De modo semelhante, na Universidade Federal do Rio Grande do Norte (UFRN), o projeto de extensão "Controle da COVID19: teleatendimento na rede de apoio ao SUS" realizou suas ações por meio de ligações telefônicas, mensagens por meio do aplicativo WhatsApp e pelo site Orienta Coronavírus RN. Nele, havia a participação de estudantes de diferentes cursos e instituições (Amancio et al., 2020).

Ademais, devido a pandemia, inúmeras instituições publicaram edital específico para incentivar ações voltadas de forma direta ao enfrentamento da COVID-19, como no caso da UERN, Fundação Universidade Federal do ABC (UFABC) e Universidade Federal de São João Del Rei (UFSJ). Para o ano de 2021, 24\% das IES publicaram edital com planos de trabalho adaptados à pandemia, levando em conta a possibilidade das atividades continuarem de modo remoto e/ou com as normas de biossegurança definidas pelas OMS. Com isso, evidencia-se os sentimentos de solidariedade e empenho com a ética em relação ao sistema de saúde e a população (Amancio et al., 2020). A baixa propensão das instituições a edital com adequações pode ser justificada pela esperança, que em 2021, houvesse uma vacina contra o novo coronavírus que permitisse o retorno das atividades de modo presencial. Tal fato se concretizou, com o início das vacinações brasileiras no mês de janeiro no território brasileiro (Brasil, 2021).

Em relação às limitações para a realização do estudo, a falta de visibilidade dada pelas instituições às ações de extensão em seus websites se mostrou como um empecilho para responder às questões abordadas, o que, de forma consecutiva, afetou a coleta de dados e os resultados encontrados.

\section{Conclusão}

Na maioria das IES as ações de extensão continuaram através de readequações e flexibilização em suas normas. Todas as modalidades de extensão continuaram sendo ofertadas com destaque para os projetos, tendo sido reduzida consideravelmente a prestação de serviços. As instituições estão planejando suas atividades em 2021 de diferentes formas, entretanto, o formato híbrido é o meio proposto com maior adesão pelas IES. Por fim, vale destacar que a continuidade das atividades de extensão 
possibilitou a realização de várias ações voltadas ao enfrentamento da COVID-19, contribuindo de forma significativa para minimizar os impactos da pandemia. Diante do exposto, pôde-se perceber que a extensão universitária cumpriu com sua função de conectar o universo acadêmico com a sociedade durante a pandemia.

Como proposta para futuras pesquisas, sugere-se a temática do impacto da pandemia da COVID-19 nas pesquisas científicas em instituições de ensino superior.

\section{Referências}

Amancio, M. A. et al. (2020). Teleatendimento à população do Rio Grande do Norte durante a pandemia da COVID- 19. Research, Society and Development, 9 (9), 1-17.

Barbosa, A. T., Ferreira, G. L. \& Kato, D. S. (2020). O ensino remoto emergencial de Ciências e Biologia em tempos de pandemia: com a palavra as professoras da Regional 4 da SBENBIO (MG/GO/TO/DF). Revista de Ensino de Biologia da SBEnBio, 13 (2), 379-399.

Bernal, H. M., Siqueira, C. E., Adami, F. \& Santos, E. F. S. (2020). Trends in case-fatality rates of covid-19 in the world, between 2019 - 2020. J Hum Growth Dev., 30(3), 344-354.

Bezerra, K. P., Costa, K. F. L., Oliveira, L. C. de, Fernandes, A. C. L., Carvalho, F. P. B., \& Nelson, I. C. A. S. R. (2020). Ensino remoto em universidades públicas estaduais: o futuro que se faz presente. Research, Society and Development, 9 (9), 1-17.

Brasil. Ministério da Educação. (2006). Qual é a diferença entre faculdades, centros universitários e universidades? Portal do Ministério da Educação (MEC). Recuperado de: http://portal.mec.gov.br/pet/127-perguntas-frequentes-911936531/educacao-superior-399764090/116-qual-e-a-diferenca-entre-faculdadescentros-universitarios-e-universidades

Brasil. Ministério da Educação. (2020). Coronavírus: saiba quais medidas o MEC já realizou ou estão em andamento. Portal do Ministério da Educação (MEC). http://portal.mec.gov.br/busca-geral/12-noticias/acoes-programas-e-projetos-637152388/86791-coronavirus-saiba-quais-medidas-o-mec-ja-realizou-ou-estaoem-andamento\#: :text=Suspens\%C3\%A3o\%20de\%20aulas\%20presenciais\%20na,atividades\%20n\%C3\%A3o\%20presenciais\%20substitu tivas\%2C\%20por

Brasil. Ministério da Saúde. (2021). Profissionais de saúde e idosos institucionalizados serão os primeiros a receber doses de vacina contra a Covid-19. Portal do Ministério da Saúde. https://www.gov.br/saude/pt-br/assuntos/noticias/profissionais-de-saude-e-idosos-institucionalizados-serao-os-primeiros-a-receberdoses-de-vacina-contra-a-covid-19

Brasil. Resolução No 510, de 07 de abril de 2016. (2016). Conselho Nacional de Saúde, Instrução Normativa nº 510/2016, que di spõe sobre as normas aplicáveis a pesquisas em Ciências Humanas e Sociais. Diário Oficial da União. https://ww w.in.gov.br/materia/-/asset_publisher/Kujrw0TZC2Mb/content/id/22917581

Brasil. Resolução n ${ }^{\circ}$, de 18 de dezembro de 2018. (2018). Estabelece as Diretrizes para a Extensão na Educação Superior Brasileira e regimenta o disposto na Meta 12.7 da Lei $n^{\circ} 13.005 / 2014$, que aprova o Plano Nacional de Educação - PNE 2014 - 2024 e dá outras providências. http://portal.mec.gov.br/index.php?option=com_docman\&view=download\&alias=104251-rces007-18\&category_slug=dezembro-2018-pdf\&Itemid=30192

Brasil. Sistema de Regulação do Ensino Superior - e-MEC. (2017). Cadastro Nacional de Cursos e Instituições de Educação Superior, regulamentado pela Portaria Normativa $\mathrm{n}^{\circ}$ 21/2017, que dispõe de uma base de dados oficial contendo os cursos e Instituições de Educação Superior - IES, independentemente de Sistema de Ensino. Recuperado de https://emec.mec.gov.br/

Campos, B. H., Alfieri, D. F., Bueno, E. B. T., Kerbauy, G., Dellaroza, M. S. G. \& Ferreira, N. M. A (2020). Telessaúde E Telemedicina: Uma Ação De Extensão Durante A Pandemia. Revista Aproximação, 2 (4), 24-28.

Diniz, E. G. M. et al (2020). A extensão universitária frente ao isolamento social imposto pela COVID-19. Braz. J. of Develop, 6 (9), $72999-73010$.

Falcão, D. \& Gomes, C. L. (2020). Estratégia e Táticas do Projeto “Cine Luce” no Contexto Pandêmico da Covid-19: o Lazer em Foco. Revista do Programa de Pós-graduação Interdisciplinar em Estudos do Lazer - UFMG, 23 (3), 27-56.

FORPROEX- Fórum de Pró-Reitores de Extensão das Universidades Públicas Brasileiras (2012). Política Nacional de Extensão Universitária. FlorianópolisSC: PROEX, p. 9. https://proex.ufsc.br/files/2016/04/Pol\%C3\%ADtica-Nacional-de-Extens\%C3\%A3o-Universit\%C3\%A1ria-e-book.pdf

FORPROEX- Fórum de Pró-Reitores de Extensão das Universidades Públicas Brasileiras. (2001) Plano Nacional de Extensão Universitária. Ilhéus: Editus, v.1. Coleção de extensão universitária.

Gusso, H. L. et al. (2020, setembro). Ensino Superior Em Tempos De Pandemia: Diretrizes À Gestão Universitária. Educação \& Sociedade, 41 , 1-26.

Jiang, F., Deng, L., Zhang, L., Cai, Y., Cheung, C. W. \& Xia, Z. (2020). Review of the Clinical Characteristics of Coronavirus Disease 2019 (COVID-19). Journal of General Internal Medicine, 35 (5), 1545-1549.

Lima, A. E., Andrade, A. F. B, Nunes, V. R. R., Vieira, S.V. \& Mélo, C. B. (2020). In Anais do I Congresso Online de Odontologia no Uniesp. Cabedelo: Editora Uniesp, http://editora.iesp.edu.br/index.php/UNIESP/catalog/view/100/91/282-1

Lopes, S. (2020, julho). Projeto do Departamento de Farmácia orienta sobre descarte correto de EPIs em tempos de pandemia. Projeto do Departamento de Farmácia orienta sobre descarte correto de EPIs em tempos de pandemia (uepb.edu.br)

Mélo, C. B., Farias, G. D., Moisés, L. S., Beserra, L. R. M. \& Piagge, C. S. L. D. (2020). Ensino remoto nas universidades federais do Brasil: desafios e adaptações da educação durante a pandemia de COVID-19. Research, Society and Development, 9 (11), 1-19. 
Research, Society and Development, v. 10, n. 3, e1210312991, 2021

(CC BY 4.0) | ISSN 2525-3409 | DOI: http://dx.doi.org/10.33448/rsd-v10i3.12991

Orte, C., Sánchez-Prieto, L., Domínguez, D. C. \& Barrientos-Báez, A. (2020). Evaluation of Distress and Risk Perception Associated with COVID-19 in Vulnerable Groups. Int. J. Environ. Res. Public Health, 17 (24), 9207.

Pereira et al. (2018). Metodologia da pesquisa científica, UFSM.

PROEX/UFPB. (2011). Entendendo a extensão: cartilha de extensão. http://www.ctdr.ufpb.br/ctdr/contents/documentos/pdf/cartilhadeextensao.pdf

Ricci, E. C., Dimov, T., Cassais, T. S. \& Dellbrügger, A. P. (2020, setembro). University experiences of occupational therapy in Brazil during the Covid-19 pandemic: Contributions and support in mental health for the population. World Federation of Occupational Therapists Bulletin, 76 (2), 75-77.

Santos, J. L. G. et al. (2020, agosto). Como os hospitais universitários estão enfrentando a pandemia de COVID-19 no Brasil? Acta Paul Enferm., 33 , 1-8.

Sá-Silva, J. R., Almeida, C. D.de, \& Guindani, J. F. (2009). Pesquisa documental: pistas teóricas e metodológicas. Revista Brasileira de História \& Ciências Sociais, 1 (1), 2175-3423.

Silva, A. G. S. et al. (2020, novembro). Extensão universitária na conscientização de doação de sangue e medula óssea em período de pandemia. Hematology, Transfusion and Cell Therapy, 42 (2), 357.

Silva, K. C. \& Kochhann, A. (2018). Tessituras entre concepções, curricularização e avaliação da extensão universitária na formação do estudante. Revista Espaço Pedagógico, 25 (3), 703-725.

Silva, M. R. F., Mascarenhas, A. L. L. D, Dutra, M. C. F. S. G, Silva, C. A. F. \& Dias, N. S. (2020). Reflexões sobre as ações extensionistas e de pesquisa no combate à COVID-19 na universidade do estado do Rio Grande do Norte. Brazilian Journal of health Review, 3 (2), 3622-3646.

Silva, S. P. et al. (2020, junho). Extensão Universitária, Economia Solidária e Geração de Oportunidades no Contexto da COVID-19: uma visão a partir de três experiências concretas no território brasileiro. Mercado de Trabalho: conjuntura e análise, 69, 1-12.

Steigleder, L. I., Zucchetti, D. T. \& Martins, R. L. (2019). Trajetória Para A Curricularização Da Extensão Universitária: Atuação Do Forext E Diretrizes Nacionais. Revista Brasileira de Extensão Universitária, 10 (3), 167-174.

World Health Organization - WHO. (2021). COVID-19 vaccines. https://www.who.int/emergencies/diseases/novel-coronavirus-2019/covid-19-vaccines

World Health Organization - WHO. (2021). Painel do WHO Coronavirus Disease (COVID-19): Situação por país, território e área. https://covid19.who.int/table 